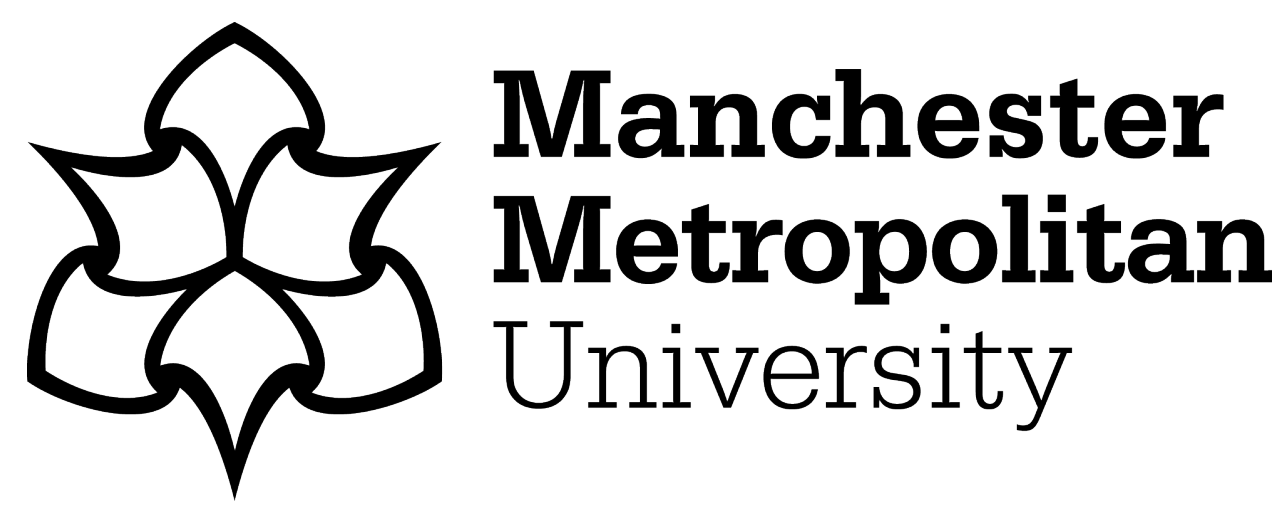

Shirley, DG ORCID logoORCID: https://orcid.org/0000-0002-5367-1647 (2018) His Dream of Passion: Reflections on the work of Lee Strasberg and his influence on British Actor Training (Part Two). Stanislavski Studies, 6 (2). pp. 165-182. ISSN 2056-7790

Downloaded from: https://e-space.mmu.ac.uk/618630/

Version: Accepted Version

Publisher: Taylor and Francis

DOI: https://doi.org/10.1080/20567790.2018.1496555

Please cite the published version 
His Dream of Passion: Reflections on the work of Lee Strasberg and his influence on British Actor Training - Part Two

\section{David Shirley}

ABSTRACT A previous article for Stanislavski Studies (Vol. 4, No 1, 47-62) explored and examined the impact of Lee Strasberg's Emotion Memory technique and assessed its influence on contemporary approaches to British actor training. This second 'companion' article reflects on a much broader range of Strasbergian training techniques in order, initially, to examine their efficacy and to highlight the extent to which they have been absorbed and adapted by acting teachers working in a British training context. Often viewed as a controversial figure - both in the United Kingdom and in the United States - Strasberg's approach has frequently been vilified and dismissed. This is particularly true of his interpretation of Stanislavski's Emotion Memory technique. Whereas the earlier article sought to arrive at an informed and balanced view of his deployment of this technique, what follows is an attempt to review other aspects of Strasberg's work so as to evaluate the coherence and credibility of the assumptions on which his approach was based and to test whether his work remains appropriate and viable in British training environments today. His work on Relaxation, Concentration and Sense Memory will be examined alongside his development of the Private Moment, Song and Dance and Animal exercises. What, if anything, can we learn from Strasberg's Method-based approach to actor training and how might we begin to consider the impact and unity of his work as a whole as opposed to focusing almost exclusively on his early work on Emotion Memory? 
Keywords: Lee Strasberg, Stanislavski, Emotion Memory, Actors Studio and Method Acting.

David Shirley trained as an actor at the Arts Educational Schools and studied at RADA. He has extensive experience of performing in theatre, film and TV and is currently Director of the Manchester School of Theatre at MMU. His research interests focus on British and American actor training, Beckett's Theatre and Contemporary Performance Practice.

Irrespective of whether or not those involved in actor training today subscribe to any of the teaching techniques that are now commonly associated with the Method-based approaches developed in the USA during the 1940s and 50s, the immensely significant impact of Lee Strasberg's work cannot be overstated. More than any other figure associated with this kind of approach (including Stella Adler, Sanford Meisner and Uta Hagen) ${ }^{1}$, Strasberg must surely stand out as the most acclaimed and influential American acting teacher of the $20^{\text {th }}$ Century. Famously identified with the Actor's Studio in New York - where he was the Artistic Director for over thirty years (195182), the founder of the Lee Strasberg Theatre and Film Institute, based in New York and West Hollywood (1969-present) as well as being credited with enabling the careers of actors such as James Dean, Marilyn Monroe, Paul Newman, Al Pacino and Anne Bancroft, his legacy has had a far-reaching impact not just in the USA, but also in Europe and beyond. Despite such influence, however, Strasberg remains a highly controversial and often polarizing figure whose work, both during his lifetime and subsequently has been revered and vilified in equal measure.

Much of the disapprobation surrounding Strasberg's teaching practice is directed at his adaptation and interpretation of Stanislavski's work on Emotion 
Memory. A variety of concerns relating to this exercise and the nuances and complexities emerging form it have been discussed in a companion article to this, published two years ago (Vol. 4, No 1, 47-62). One of the dangers, however, in focusing almost exclusively on a single feature of his methodology, is that it can lead to a skewed understanding of Strasberg's approach to teaching more generally. The following commentary by John Harrop, for instance, is fairly typical of the frequently negative evaluations of Strasberg's work:

Emotion memory is essentially second-hand. It uses emotion that is stimulated by a circumstance other than that of the play's immediate action. It introduces an emotional non sequitur into a performance. It can produce irrelevance - the actor is involved with a past situation of his or her own, rather than responding to the action of the present and thus may transmute the part into the structure of the actor's own, possibly different emotional needs and dynamics. (Harrop 1992: 40-41)

Even more damning is the following observation by Richard Hornby: 'Strasberg's emotion memory...can be seen partly as a cause, but even more as a result, of the decline of the American theatre'. (Hornby 1992: 184)

In order to arrive at a fuller and more informed understanding of Strasberg's teaching methods and thereby begin to assess the extent of his influence in Britain, it is necessary to take a closer look at some of the other techniques and exercises he developed. Revealingly, the highly 'integrated' nature of Strasberg's version of the Method, in which different elements overlap and complement each other, suggests that whilst the Emotion Memory technique represents an important aspect of his practice, it 
is by no means his primary focus. American acting teacher and former Strasberg student Ned Manderino confirms this view:

My own experience with this issue is based on six years of student with Strasberg in his private workshop and at the Actors Studio. Contrary to what is frequently proclaimed, I cannot honestly conclude that Strasberg's teaching was overloaded with the use of the affective memory exercise. Although Strasberg may have emphasized the affective memory exercise during the fifties, this was no longer the case by the time I studied with him in the 1960's. During this period, I saw it done only twice and both times, Strasberg was very much in control of the emotion that surfaced. While I studied with him, Strasberg was primarily concerned with the sensory technique exercises, which nearly all Method acting teachers deem essential to an actor's development. Strasberg taught a means of making the acting instrument come alive with a basis of organic truth. (Manderino 1985: IX)

Manderino's reference in the final sentence to the 'acting instrument' chimes with the more contemporary observations of Sam Rumbelow, Director of London's Method Acting School (MAS), based in Central London. For him, it is this emphasis on the instrument that is at once the most important, yet also the most misunderstood aspect of Strasberg's craft. 'Strasberg's approach to training stresses the need to develop the instrument. His process is varied and multi-layered and is concerned with enabling the actor's relationship to his/her instrument in order to free the ability to relate to the task of the actor.'2

Rather than address the demands of style or the expectations of a particular genre or tradition in acting, Strasberg's emphasis on the actor's instrument takes immediate account of the individual needs of each actor. Of course, most serious actor training 
courses - especially within a conservatoire tradition - claim to do the same. As Rumbelow makes clear, one of the things that makes Strasberg's approach unique is its commitment to the notion of developing expressivity based in selfhood as distinct from the transformative performance skills that are commonly associated with the classically trained virtuoso /chameleon like actor. 'For Strasberg, acting is defined by the ability to have truthful thoughts and impulses by means of a primary flow of the self ${ }^{3}$

The starting point from which all of Strasberg's work proceeds is his emphasis on the need for relaxation. Recognizing that physical tension impedes gestural and emotional expressiveness and blocks the free flow of thought, Strasberg, like Stanislavski, also drew a contrast between the obvious forms of tension of which we are aware (vocal tightness and fixed muscularity) and more habitual, unconscious forms of tension (repeated mannerisms, personal anxieties/worries, etc.). Strasberg believed that unless actors find a way of overcoming the disabling problems presented by tension, even their best efforts would remain thwarted:

Without relaxation a lot of things an actor may rightly want to do will be deformed as they enter his instrument, because the instrument itself sets up resistance through tension. When that happens, the actor cannot achieve a real relation between what he is thinking and the expression which should be part of that thought or experience. The expression becomes contaminated. (Robert H. Hethmon 2010: 89)

Believing that the '...basic habitual behavior of human beings leads to the habitual behavior of the actor' (Lola Cohen: 2010:6), the relaxation techniques developed by Strasberg are designed to enable the following: 
- The removal of both physical and mental forms of tension

- The promotion of enhanced emotional freedom and an uninhibited flow of thoughts

- Increased levels of physical ease and gestural expressivity

- The ability to recognize and be aware of the presence of tension and how to eradicate it.

In many ways, Strasberg's relaxation techniques bear a close resemblance to those recommended by Stanislavski. By finding a position - either sitting or standing - in which to relax physically (without falling asleep) and focusing on and working with individual muscle areas, it is possible to experience a sense of physical relaxation. Gradually, over time and with practice, it becomes possible to reach such a state quickly and with relative ease. Interestingly, however, Strasberg takes relaxation a stage further by advocating a series of exercises designed to release mental forms of tension - which, he suggests, are often unconsciously present in our use of gesture (hands, fingers, etc.) or facial expressions (eyebrows, mouth, etc.). Whilst he certainly acknowledges that physical tension is much easier to observe than mental tension, Strasberg moves on to identify various areas of the body that he describes as 'indicators of mental tension'. An assertion, he claims, that does ' ...not stem from theory or scientific observation but purely from practice' (Hethmon 2010: 91). The areas in question are firstly, the temples, where 'lots of nerves and blood vessels feed into the brain'; secondly, the area leading from the bridge of the nose into the eyelids, where the automatic defense mechanism for the eyes is so active 'that a great deal of tension builds up'; thirdly, the area round the mouth, where thoughts 'are immediately reduced to words' and where, as we grow older 'there are a lot of things you feel like saying but don't say'. Finally, the fourth 
and 'central area of mental and physical tension' is located in the muscles joining the shoulders, the back of the neck and the cranium, where there can be 'a severe bottleneck of tension that is very difficult to deal with' (Strasberg: 1988:128). ${ }^{4}$

Like Stanislavski, Strasberg believed that all forms of tension inhibit freedom of expression and the ability to convey emotion. By extending the principles of Stanislavski's work and advocating a system for dealing with mental tension, Strasberg seems to have arrived at a way of tackling the habitual, unconscious modes of behavior that can block creativity:

Neuromuscular tension makes it difficult for thoughts, sensations and emotions to be transmitted and properly experienced. Often an actor is experiencing the emotion he is working for but is unable to express it because of tension. I remember an actor who delivered a speech from a Shakespeare play which seemed external and mechanical. When he explained what he had attempted to do, it seemed impossible to believe him because we had seen none of it in performance. When we made him relax properly, and then while maintaining the relaxation deliver the same speech, suddenly is was alive and convincing. (Strasberg 1988: 126)

What makes this sequence particularly interesting is the gap it opens up between what the actor may think is being communicated - a physical and vocal sense of ease, a convincing emotional connection and a credible characterization - and what is actually being conveyed. Merely because an actor experiences a particular emotion, it does not necessarily follow that this is visible to the spectator. Most actor trainers will recognize those situations in which following an unsuccessful attempt at a given exercise or scene, an actor will protest that s/he really was crying or feeling elated. It is as if the feelings 
that are actually being experienced remain trapped behind a wall of tension. For Strasberg, the removal of this wall produces startling results:

Sometimes the talent of the actor reveals itself for the first time so fully and so unexpectedly as to be startling. The actor becomes completely responsive. His instrument gives forth a new depth of resonance. Emotion that has been habitually held back suddenly rushes forth. The actor becomes real - not merely simple or natural...He unveils totally unexpected aspects and elements of himself, but with such a degree of ease and authority that he seems literally to have taken off a mask, to have emerged from a disguise that previously had smothered and concealed his true personality. Yet all he did was relax. (Robert H. Hethmon 2010: 93)

Relaxation represents the starting point for Strasberg's methodology. Whilst Sam Rumbelow suggests that ' ... it represents the core around which the rest of his work is built and removes the fear of failure or the need for validation', ${ }^{5}$ Peter McAllister, an actor trainer based at London's Royal Central School of Speech and Drama (RCSSD) emphasizes the importance of relaxation in helping 'to remove fear and promote freedom from self-consciousness ${ }^{6}$.

If relaxation establishes the foundations on which to begin Strasberg's work, then concentration, he argues '...releases the actor's creative spirit' (Hethmon 2010:95). For Strasberg, as with Stanislavski, concentration is defined by an actor's ability to focus the mind either on an individual object or collection of them. Whilst an object can be something material - such as a picture or an ornament - it can also be a recollection of something immaterial such as a feeling or sensation. An object can even 
be imagined - a pain, for instance, or a sense of longing or melancholy. Whereas Stanislavski, via his Circles of Attention, extends the work on concentration to enable actors to overcome a fear of the 'black hole' that is the audience (Stanislavski 2008: 93), Strasberg's work in this area focuses almost exclusively on the development of an actor's sense memory - something to which we will return later. In part, this may be a result of the different contexts in which each teacher was operating. Stanislavski's methods were largely developed for theatrical performance practice, whereas Strasberg, though very experienced in theatre, established an illustrious reputation for training highly successful screen actors. Though intense concentration is required of actors in both mediums, the specific demands of the screen are less preoccupied with the physical presence of an audience.

In his book, A Dream of Passion (1988: 131), Strasberg offers a very clear definition of what he expects from a process of concentration:

To concentrate, one must have an object of concentration; one cannot concentrate abstractly. The simple presence of an object will not induce concentration. If you look at a chair and try to concentrate, nothing will happen. If you start asking yourself simple questions - How wide is the chair? How tall is it? What is it made of? And so on simple concentration will take place. But that, actually, is more a process of observation. The kind of concentration necessary for acting demands the ability to recreate something which is not there. It leads not only to the workings of the imagination, but also to the presence of that kind of belief or faith which has often been characterized as the essential element of acting'. (Strasberg 1988: 131) 
Interestingly, despite the criticisms of many, who have argued that Strasberg's teaching methods frequently veered away from Stanislavski's vision, there is a clear sense of continuity between the two men when it comes to concentration, as is evidenced in the following observation by Stanislavski:

As far as technique is concerned you have to first find, recognize, study and learn to master it. For the moment use things you have already experimented with...I am talking about ways of giving the imagination a jolt...

...ask yourself questions and answer them honestly, sincerely: the who, what, when, where, why and wherefore of what you observe happening. Define in words what you find beautiful, typical in the room, in the things which interest you... Define the purpose of the room, the articles in it. Ask yourself and answer, why is the furniture arranged this way and not some other way.' (Stanislavski 2008: 116)

As is the case with Strasberg, Stanislavski points to the need for concentration as a way of stimulating the creative and imaginative processes alive in the actor:

The genuine actor is set on fire by what is happening around him, he is carried away by life, which then becomes the object of his study and his passion. He greedily devours everything he sees and tries to record what he has registered, not like a statistician, but like an artist...In a word, in art you cannot use a cold approach. We need a certain degree of inner fire, we need sensory concentration'. (Ibid: 115)

For Strasberg, Relaxation and Concentration represent the 'heads and tails' of what Lola Cohen has referred to as 'the coin of acting' (Cohen 2010: 5). These are the primary building blocks on which all of his subsequent work is established. In many 
respects, this part of Strasberg's methodology bears a striking resemblance to Stanislavski's. Indeed, even his reference to the challenges faced when attempting to concentrate at times of physical strain are almost a carbon copy of Stanislavski's work - as can be seen from the following extracts:

Can I persuade you that physical tension paralyses our whole capacity for action, our dynamism...Let's do an experiment. Up onstage there's a piano, try and lift it...Multiply 37 by 9 quickly, while holding up the piano...You can't? Well then remember all the shops in our street from the corner of the lane onwards. You can't do that either?...Doesn't this demonstrate how muscular tension impedes our thinking, and the process of experiencing even more?' (Stanislavski 2008: 121)

It is easy to experience tension by trying a simple experiment. Try lifting something heavy, such as edge of a piano or a heavy table. At the same time try to solve a simple mental problem, such as multiplying 75 by $6 \ldots$ You will discover that it is nearly impossible to do so while lifting a heavy object...If you attempt to recite a poem or sing a song or remember something, you will find it an insurmountable task...Neuromuscular tension makes it difficult for thoughts, sensations, and emotions to be transmitted and properly experienced.' (Strasberg 1988:125)

At a first glance at these extracts, it might be tempting to conclude that Strasberg's version of the Method is a slavish re-packaging of Stanislavski's System, but it is important to bear in mind two considerations. The first, as we shall discover, is that whilst Strasberg wholeheartedly subscribes to the spirit of Stanislavski's work, the nuances and interpretations he brings to it are very much the product of his own experiences and research: 
The work which I present can now legitimately be called the Method. It is based not only on the procedures of Stanislavski's work, but also on the further clarification and stimulus provided by Vakhtangov ${ }^{7}$. I have also added my own interpretation and procedures. (Strasberg 1988:84)

Secondly, some critics have argued that Strasberg's work is a betrayal of Stanislavski's ${ }^{8}$, but as can be seen here, Strasberg clearly acknowledges the extent of Stanislavski's influence: 'Everything we deal with in these exercises - relaxation, concentration, sense memory, emotional memory - was defined by Stanislavski.' (Ibid:124)

Some of the distinctions between Stanislavski's work and Strasberg's begin to emerge in the latter's work on sense memory, and the private moment exercise.

Sense memory work is common to most actor training regimes, and Strasberg's version of the Method is no exception. Designed to enable the actor to '...recreate and re-live...the desired experience called for in the performance' (Cohen 2010: 14), these exercises are arranged in a coherent sequence that starts with fairly basic tasks that involve recalling the sensations associated with material objects before moving through to more intense exercises that involve recalling a number of sensations simultaneously. These can be drawn from physical materials and feelings, past memories or even fantasies. What is particularly striking about Strasberg's approach - as distinct from other Method practitioners, notably Uta Hagen, for instance ${ }^{9}-$ is his emphasis on the imagination as the primary tool for developing and awareness and sensitivity.

Prop kettles and other literal objects not only stop the actor's training by blocking real imagination, but make him revert to ordinary, literal habits of behavior. In life those 
habits do not matter too much...On stage there are no real objects - except these literal stage properties - and thus there is no strong and real continuity outside the actor to bring him alive. If we rely only on these literal objects, we tend unconsciously to use literal habits of expression. The very thing we are trying to create dies, because after all it is not actually real.' (Robert H. Hethmon 2010: 101)

As Peter McAllister notes, unlike other sense-based exercises, Strasberg's activities emphasize the importance of imagination rather than endowment Whilst the latter approach might attribute a particular imagined quality to an object - rarity, fragility, beauty, etc. - the requirement to imaginatively reconstruct the object itself before subsequently layering it with additional sensory experiences - touch, taste, smell, sound, etc. - serves to really develop, focus and sharpen an actor's imagination. American Strasberg teacher, Lorrie Hull emphasizes the point:

When an actor creates an imaginary object, he gets more than that object. He gets his response to the object, so that he has in effect created a particular aspect of himself. When the actor creates the object's reality, he knows he has succeeded if he is visualizing the object and feeling the sensations. The body will perceive the object as real because the person gets the same sensations from the physical object. In acting, the source is imaginary, but the responses are real. That is what creates a belief of sense of truth in the actor.' (S. Loraine Hull 1985: 43)

It is important to point out that these activities are not 'mime' exercises. Instead of simply imitating a given activity - brushing hair or drinking coffee - the aim is to recall and recreate in as much detail as possible the stimuli associated with the chosen 
task (textures, tastes, smells, sounds), as well as the muscular movements accompanying it (the feel of the brush and movement of the head or the pursing of the lips for a hot drink).

Broadly speaking, Strasberg's series of sense memory exercises can be divided into three categories:

\section{Physical Exercises involving Muscular Movement}

These exercises tend not to involve emotional engagement, focusing instead on mundane daily tasks like consuming hot/cold drinks; grooming activities such as applying make-up/shaving; or dressing and undressing. Although at one level, the exercises feel fairly basic, the ability to recall and recreate the experience of drinking a hot cup of morning coffee or having a shave involves the need to engage all five senses simultaneously. This requires considerable perseverance and dedication.

\section{Exercises Exploring Physical Sensations}

These exercises develop the skill of recalling physical sensations such as heat and cold, sharp tastes and smells, or the experience of pain. Importantly, the sensation arising from recalling these experiences should not be taken to extremes. Wherever possible, emotional responses should be avoided in favour of simply capturing, in as much detail as possible, the experience of the sensation itself.

\section{Exercises Involving Multiple Activities/Senses and Exploring the Use of Emotion}

These exercises bring complexity to the work and require the actor to balance several activities - physical, sensory and emotional - simultaneously. They really stretch the imagination and prepare the way for the development of dramatic character and improvisation/scene work. 
Although Stanislavski also used a range of sense-based exercises, Strasberg's extremely detailed approach to this work was designed to stimulate real responses to imagined realities. For instance, an actor might actually shiver in response to an imagined sense of extreme cold or experience genuine embarrassment as a result of his/her imagined nakedness before stepping into an imaginary shower. Promoting enhanced powers of concentration and focus as well as the ability to work in extreme detail for sustained periods, these exercises helped established the foundations for the psychological depth that became one of the hallmarks of the Method.

It is interesting to note at this point, that whilst Strasberg's approach to actor training is heavily influenced by Sigmund Freud ${ }^{10}$, his conviction that imagined circumstances can generate real experiences is strongly Pavlovian in character. The shivering an actor might experience when recalling a sense of extreme cold feels strongly reminiscent of Pavlov's food associative experiments in which dogs salivated at the sound of a particular chime. Unlike animals, however, actors seek to consciously stimulate responsive processes in themselves. Revealingly, it is this feature of Strasberg's work that enables us to arrive at a fuller understanding of his development of the emotional memory technique:

Sense memory is not returning to the past to remember your dead pet so you can cry in a scene. This is a misunderstanding of the work. Based on Dr. Ivan Pavlov's turn-ofthe century experiments in Russia, sense memory is a technique that helps actors believe a reality that in fact doesn't exist in the present. This conditioned response helps actors achieve real sensory experiences that are, in fact, non-existent.' (Doug Moston "Standards and Practices" in Krasner 2000: 137) 
Strasberg's himself makes the point clearly: 'Emotional response is conditioned response. It can be evoked by concentration on the factors associated with the particular conditioning process'. (Robert H. Hethmon 2010: 113)

The various sensory exercises Strasberg developed and his emphatic insistence on the primacy of the imagination in applying them, represent a fundamental feature of the conditioning process that he believes is essential to 'truthful' acting. In this context, the notion of 'truth' is defined by the actual presence of the feelings evoked by a particular sensory experience rather than a projected imitation of them. Understanding this principle in relation to Strasberg's work is important if we are to arrive at a more informed awareness of the emotional memory technique and how it sits within Strasberg's practice more generally. As Doug Moston clearly indicates, sense memory is not simply a case of delving into past experiences in order to capture a particular emotion or feeling - such a supposition is simplistic and reductive.

Although, in general terms, Method based acting techniques tend to stress the importance of psychological/behavioral realism, Strasberg's early exercises are refreshingly free and non-literal. Peter McAllister offers an excellent example of this in his combined use of 'overall sensations' and 'personal object' exercises. In his acting classes at the Royal Central School of Speech and Drama, students may find themselves having an imaginary shower whilst reading an important letter or nursing an injured pet - a cat, for example. Rather than allowing students to become trapped or overly fixated by what is or isn't logically possible/coherent, McAllister's approach - which draws directly form Strasberg's own - is designed to free the creative spirit and stretch the imagination. 'Sensory work is never literal and never copied, it must always be highly 
imaginative. There is absolutely no need to get caught up in realist questions. This work enables access to the imagination through the senses. ${ }^{11}$

Whilst the sequence in which the exercises are presented suggests a chronological order, Strasberg's own teaching practice, remained highly responsive to the individual needs of his students. If a particular exercise didn't work for an actor, then he selected another that might achieve a similar result.

The continuity and sequence of the exercises is not hard and fast and can't be done by rote. There's an individual approach for each actor, and a general sequence of the exercises which the teacher adjusts to each individual... The teacher only changes the sequence, however, if there is something the actor can't do. It may include deliberate diversions using other procedures if there is a particular problem to deal with... Some people go quicker, and then the teacher moves them ahead, but the teacher shouldn't challenge the actor.' (Lola A Cohen 2010:16-17)

Complaining that '...too many teachers push the actor to accomplish immediate results without permitting him to exercise his faculties, to get in shape.' (Strasberg 1988: 135), Strasberg urged a flexible and dynamic application of exercises that enable recognition and differentiation between muscular and sensory work. In some instances, actors who experience difficulty with complex exercises are taken back to earlier activities as a means of building sensitivity and promoting confidence. What is especially striking in the work of both Peter McAllister at RCSSD and Sam Rumbelow at MAS is their insistence on the need to remain responsive to the needs of individual students rather than deliver a chronologically ordered programme of exercises. As 
McAllister makes clear, this work is about '...imparting tools, not rules, that are designed to connect the actor's impulse to varying means of expression'. ${ }^{12}$

Notwithstanding the intended developmental nature of these exercises, there can be instances when even the most proficient actors experience genuine difficulties when attempting to work with sense memory and the imagination. Often this may be a result of natural inhibitions, feelings of tension or of what Strasberg refers to as 'lockedup sensations' (Ibid: 139). For actors faced with problems of this kind, Strasberg developed the Private Moment exercise. Emerging from Stanislavski's discussion of 'public solitude', ${ }^{13}$ this exercise is designed to allow for enhanced degrees of concentration that will open up new areas of expression and self-discovery. 'Part of the function of the private moment...' Strasberg states '...is to permit the actor to...give himself fully and unself-consciously to the experience that is being created.' (Ibid: $145)$.

The use of the word private in the context of this exercise has a very particular meaning for Strasberg:

Privacy is not to be confused with being alone. One can be alone and not in private...A private moment is not characterized by the nature of what takes place, but by the particular sense of privacy which it possesses for the actor who expresses it...The actor chooses a certain behavior in his life which he does only in private, and at no other time. He feels so special about this behavior that he stops it if he is interrupted by the appearance of another person. If he is questioned about it, he will deny that anything unusual has taken place. (Ibid: 145) 
Although the tasks chosen for this exercise should be those that would normally take place in private, they should not be extraordinary or beyond the bounds of good taste. Typical examples might include dressing/undressing, gazing in the mirror, joyously singing or dancing without inhibition, thinking about a problem, praying, meditating, cutting toenails or shaving body hair. In the event of a situation where an actor appeared likely to stray beyond the boundaries of good taste, Strasberg required him/her to '...complete that part off stage and then come back' (Robert H Hethmon 210: 119). The important thing is to aim to get as close as possible to the moment of privacy.

Unlike other exercises in the sequence, actors are permitted to use small objects and possessions in this exercise. Such items may include photographs, books, items of clothing, etc., that help to recreate the actual environment in which the private moment is located as well as serving to sharpen the concentration. Larger items of furniture are recreated through the use of imagination and sense- memory - sight, sound, smell etc.

According to Strasberg, this exercise produces startling results:

We started to do this exercise and two things happened. The exercise produced wonderful results in the actor's belief in what he was doing, and it led to a releasing of emotion and a degree of theatrical energy I had not previously seen in these particular actors. Somehow the objects of the exercise, drawn as they were from the individual's peculiar activity, were strong enough to incite this kind of concentration. At the same time the improvisational nature of the exercise left them free to follow through what they were impelled to do. (Robert H Hethmon 210: 116). 
Aside from making a decision about what the private moment should involve and selecting small possessions to help re-create the space, this exercise should not be rehearsed. The improvisational approach is designed to enable the actor to make genuine discoveries in the live moment. Students are encouraged not to avoid any activity that may cause embarrassment or self-consciousness. Feelings of this kind arise as a result of an awareness of the audience, which should give way to complete concentration and absorption. If an actor undertaking the activity is aware of those watching, then the purpose of the exercise is defeated.

Gradually, as proficiency and confidence with this exercise develop other Strasbergian techniques can be introduced, so that it is possible to combine a private moment exercise with single sense memory activities, overall sensations, song and dance work or even soliloquies and speeches.

I had always thought that regardless of any degree of reality, soliloquies were only a theatrical device...It was my shock and surprise to discover how much people soliloquized in real life; how much they engage in imaginary confrontation with other people with a fullness and vividness which they could not summon in public under the actual conditions. Therefore, in addition to whatever value this exercise possesses for the actor, it is of enormous benefit in helping him to play precise scenes involving soliloquies - not only in Shakespeare and the classics, but also in Chekhov, where there are many moments which are the equivalent of soliloquies. (Strasberg 1988: 146)

When effective, the private moment exercise can begin to release actors who experience difficulty as a result of an inability to relax or feelings of self-consciousness. 
When concentration is enhanced and focused in the way the exercise demands, it can lead to self-discovery, sharpened levels of physical and vocal expressiveness, and a greater sense of freedom. Moreover, as Strasberg's observations about the soliloquy imply, the exercise is highly adaptable and can be used as a springboard into many interpretative situations - both in rehearsal and in performance.

The need for expressive freedom and the ability to work truthfully and without tension or inhibition represent core principles on which Strasberg's teaching practice was established. For some actors, it may be the case that unconscious habitual tendencies or fixed physical rhythms limit the scope for genuine creative freedom. In such situations, Strasberg introduced the Song and Dance exercise. Following a teaching assignment at Carnegie Hall, where he found himself instructing singers and dancers, he was struck by the degree to which the tempi of the musical rhythms they had previously learned and embodied served to snare them in unconscious and restricted modes of expression. In developing this exercise, Strasberg sought to find the means by which to free previously conditioned impulses and thereby further enhance physical, vocal and emotional expressivity. His aim was to highlight the extent to which unconscious habits and behavior interfere with an actor's ability to communicate with an audience:

An actor often does not do everything he wants to do. His intentions are deflected by habits of which he is unaware most of the time. Instead, he often does things of which he is equally unaware because they are mannerisms - automatic and unconscious behavior. The essential part of the actor's training tries to make him aware of what he is doing at the time a thing is happening. Otherwise, he doesn't know whether to do it 
more or to do it less. That's the difference between acting and life...for the actor it is absolutely essential that he knows all the time "what I'm doing while I'm doing it.", (Robert H Hethmon 210: 116).

Designed to stimulate increased degrees of self-awareness and limit unwanted interference from involuntary behavioral patterns, the exercise involves three phases: The first requires the actor to stand in a relaxed and open position in front of the tutor and the class. Posing should be resisted and eye contact should not be avoided or forced. Once in this position, attention is drawn to what the actor is feeling emotionally. Selfquestioning is encouraged - 'What is this? What kind of sensation is this? What kind of experience is this? What is it really? Is this one kind of reaction or another kind? Is it fear or embarrassment? Or is it shyness or anger? What am I angry about?' (Hethmon: 2010:164). In this part of the exercise, the actor's attention is drawn to the ways in which emotional energy can influence physical expression.

In stage two, the actor chooses a simple song which is then broken down into single elongated syllables which are sung resonantly - from the lungs rather than the throat - in equal breaths. In this phase, it is important to resist the temptation to speed up the tempo or to join syllables together - the aim is to break expected/habitual rhythms and afford the actor control over what is being expressed.

The third and final stage of this exercise introduces movement - usually involving the whole body. Once the rhythm of this is established the song is reintroduced only this time with more of a staccato rhythm. The combination is then regularly altered so as to create contrasting energies between the rhythms of the body 
and the energy of the voice. In this phase, the importance of the actor's will-power is highlighted as a primary means of controlling and varying patterns of physical and vocal energy.

Due to the fact that this task is designed to forge a much stronger connection between an impulse and its expression, the exercise often gives rise to unexpected emotions - laughter, tears, anger, etc. - which for Strasberg, demonstrated that '...standing before the public would start many things going on in the actor, even when he was called upon to perform a seemingly simple task' (Strasberg 1988:155). What makes this observation particularly interesting is the realization that, for Strasberg, the process of freeing an actor's impulse in order to enhance expressivity, may often involve the release of other kinds of repressed or controlled emotional responses which also appear to emerge involuntarily. Such feelings are entirely admissible, and part of the process requires the actor to '...let the emotion go into the sound of the song.' (Ibid). For Strasberg, it seems that one of the defining features of effective training and ultimately of 'good' acting is a willingness on the part of the tutor and the actor to risk exposing feelings and instincts that might otherwise remain repressed. In developing the Song and Dance exercise, Strasberg believed he had found the perfect tool for managing such behaviors:

...through this exercise we were able to see farther inside than we had ever seen before. Actually, these rather simple exercises turned out to be an X-ray into the problem of will and the relation of will to consummation, that is, to the ability on the part of will to carry through what the actor is trying to perform. (Hethmon: 2010:163) 
The exercises and techniques discussed above tend to focus on developing the psychological dimensions of an actor's work - through concentration, the senses, impulse work and the emotions. However, Strasberg also stressed the need to develop the ability to shift physical energy and inhabit different personality traits. In group work, for instance, he often set up improvisations where individual actors were asked to play out specific physical characteristics - e.g. aggression, illness, or suspiciousness - or, alternatively, to represent personalities with different kinds of professional background - farmers, students, medics, etc. ${ }^{14}$ Rather than settle for generalized impressions in this work, improvisations were carefully designed so as to facilitate new discoveries about the play, the characters or the dramatic situation that was under investigation.

Perhaps the best illustration of Strasberg's work on developing the actor's ability to transform physically as well as emotionally is the Animal Exercise. Initially introduced to this work at the American Laboratory Theatre by Russian émigré Maria Ouspenskaya, Strasberg considered it an essential component of his training regime:

This exercise trains the actor by forcing him to deal with the character's behavior rather than relying on his own feelings. Sometimes with individuals who have a strong subjective streak, and whose emotions lead to static behavior, we use this at an earlier stage to get them away from their own subjective feelings and to strengthen their mental and physical attributes. (Strasberg 1988: 147)

Having identified a particular character trait that the actor wishes to explore in a role, she/he then chooses an animal that in some way physically embodies such a trait - e.g. a tiger for aggression or a bear for strength. Rather than merely imitate the animal, 
the aim is to capture a sense of how the animal's weight, posture, tempo, etc., shape patterns of movement. This involves close observation of the differences between the actor's own physical life and that of the animal and the sense of alienation that results focuses attention on the importance of detail. When the physical energy of the animal is absorbed, the work moves into an emotional sphere involving representations of how the animal might be 'feeling' through particular gestures or segments of dialogue. At this stage of the exercises, the actor has resumed human form, but retains the personality of the animal and allows it to influence his/her physical, vocal and emotional behavior.

Rather than use the 'humanness' of a given role as a starting point for interpretation ('I am a young woman and so is the character'), this exercise opens up other ways of conceiving of and physically inhabiting character:

Because he has to choose definite elements in order to create the animal, he finds that the exercise becomes an entrance into the problem of physical characterization. He varies his normal being, takes on characteristics he does not normally have - in walk or rhythm or behavior or attitude. The exercise thus gives the actor elements he would have difficulty finding as vividly with in the human sphere...' (Hethmon: 2010:104)

An ideal exercise for affording an opportunity for actors to discover different kinds of physical energy and emotional expressiveness, this exercise enables the actor to achieve a convincing transformation into character without dependence on purely externalized mannerisms or behavioral traits. At the very core of this task is the need to observe behavior, connect with the imagination and anchor expressiveness to impulses that are defined by the needs of the character and the given circumstances of the scene/play. Whilst it may be true that the representation of an animal's feelings or mood 
can only ever be metaphorical in nature, the very fact that such a process prompts engagement with the imagination moves interpretation beyond the everyday, literalness of the world inhabited by the actor.

During the course of this discussion, the primary focus has been on Strasberg's training techniques as distinct from his approach to working on text or the methodology he used in rehearsal - both of which represent extremely important aspects of his teaching methodology. Notwithstanding this realization, however, it is evident, from the range of exercises covered and the flexible nature in which they can be applied, that his work embodies a highly integrated and coherent approach to actor training. Whilst it is true that - in common with all Method teachers - his approach is heavily indebted to Stanislavski, it is also very clear that Strasberg sought to refine and adapt his own approach to meet very particular aims. This is especially true, for instance, of his multifaceted approach to sensory work, or his development of the Private Moment or Song and Dance exercises.

Perhaps the thing that stands out most distinctly in Strasberg's approach is his focus on an actor's need to find a truthful and open connection to selfhood as a basis for expression. At times, it seems that this can appear uncomfortable or intrusive. The intense and highly personal nature of the Private Moment exercise, for instance, or the emotional release that actors sometimes experience during Song and Dance exercise. Equally important in this regard, was Strasberg's tendency to adopt the manner of a psychoanalyst in his classes - something that was discussed in fuller detail in the companion article to this (Vol. 4, No 1, 52-3). However, once we separate any 
speculation about Strasberg's personality as a teacher form a consideration based purely on the exercises themselves, the coherence and clarity of his approach is striking.

The Stanislavskian techniques he adapted as well as those he devised provide a systemized approach to training, which is cognizant not only of the professional contexts in which actors work, but also of the developmental needs of each individual student. His techniques for mental and physical relaxation, for instance, foster an ability to direct and focus energy and attention; his integration of various approaches to sensory work serve to stimulate and stretch the imagination and enable work with real or imagined objects and connection to the actor's impulse; the release of selfconsciousness, which often serves to paralyze an actor's creativity, is tackled through the Private Moment exercise, which also prompts self-revelation and discovery; the Song and Dance exercises helps to increase self-awareness, break habitual rhythms and thereby promote a greater sense of interpretative choice and control. Finally, the Animal Exercise, by emphasizing the importance of intense observation as well as outer and inner incorporation, fosters a penetrating approach to character transformation.

Importantly, the highly flexible manner in which Strasberg applied his working methods ensured that his focus was always on the individual actor's needs rather than on the efficacy of the exercises themselves. Each of the major publications that describe his work ${ }^{15}$ clearly testify to the adaptability of his approach and his unwavering focus on the very particular needs of each student.

It is true, of course, that the ability to work truthfully and expressively with emotion is one of the defining features of Strasberg's Method, but none of the exercises 
discussed above require the actor to delve into uncomfortable areas of the psyche or to resurrect troubled events in his/her past life. On the contrary, as the discussion of the Sensory exercises makes evident, Strasberg concentrated on the need to find ways of enabling actors to work with conditioned emotional responses that could be developed and utilized in the service of the imagination. In order to undertake such a task, it is important for actors to avoid the temptation to 'block' the flow of emotion as a result of physical or mental tension, of self-consciousness/embarrassment or as a result of a weak imagination.

Given the above observations, what new thoughts, if any, emerge in relation to the Emotion Memory exercise? S Loraine Hull's citation of American Psychologist Michael Schulman's scientific insights to the technique offers an interesting perspective:

In a more complex exercise called affective memory, the actor re-creates the stimuli that were present during an emotional experience in his own life. This form of emotional memory, like hypnotic age regression, involves response to imaginary stimuli. The actor tries to re-experience the specific stimuli of the past event instead of simply recalling the event or remembering the emotion. He seeks to recapture the specific sights, smells, sounds, and tactual sensations that provoked the emotion he wishes to express. The actor uses affective memory to evoke the most powerful emotions...There is evidence that the internal work produces corresponding physiological changes in addition to affecting the actor's subjective experience.

(Michael Schulman, from "Backstage Behaviorism” in Psychology Today, June 1973, pp.51-54 88. Cited by Loraine S. Hull 1985:83) 
What makes this observation particularly revealing in the context of the present discussion is the suggestion that, like other Strasbergian sense-based exercises, Emotion Memory work is aimed at recapturing the stimuli surrounding a particular event rather than simply reproducing a raw emotion. In this regard, it seems an entirely logical progression from earlier sense-memory based exercises - which aim to develop the actor's ability to recreate imagined sensory experiences as a means of generating real emotional responses.

It has often been suggested that the controversy surrounding the Emotion Memory exercise is based on a series of misunderstandings. These include accusations about the highly 'subjective' and 'intrusive' nature of the technique; Strasberg's 'pseudo-psychoanalytical' approach to the teaching of the exercise; or the tendency for the technique to encourage actors to restrict character interpretation to the confines of their own personalities. ${ }^{16}$ When considered in isolation, such criticisms feel very persuasive. However, when viewed as a single element in a systemized and progressive training regime, the exercise feels much less problematic.

It is important at this point to note that in many respects the raison d'etre informing Strasberg's work on emotional expressivity was the desire to avoid the mannered, externalized imitations of emotions that he felt were prevalent in more conventional styles of acting - notably those of the English acting tradition. ${ }^{17}$ When considered in the context of his work as a whole, the Emotion Memory exercise provides the means by which both the actor and the audience can experience emotion as an authentic, internal experience rather than externalized, imitated behavior. The crucial element that needs to be understood, it seems, is the actor's role in actively 
stimulating and creatively adapting such emotion by means of the imagination, rather than simply aiming simply to re-experience past experiences.

Ultimately, whatever our feelings about the Emotion Memory technique, it seems important to view this aspect of Strasberg's work as part of an integrated system of training in which the component parts have been designed to meet the varied needs of the individual actors seeking to foster a stronger sense of integrity and authenticity in relation to their craft.

As we discovered in the previous article, despite the controversy that often surrounds his work, Strasberg's techniques continue to be used in various drama schools and colleges in the UK. Examples include Rose Bruford College, where acting tutors Thomasina Unsworth and Julian Jones work with sense memory exercises; the Royal Central School of Speech and Drama, where Peter McAllister utilizes all of the techniques and exercises that Strasberg developed; the Drama Centre, London, where Annie Tyson works with Emotion Memory and where David Jackson deploys some of the other techniques Strasberg developed. Other notable examples include Sam Rumbelow's Central London based, Method Acting School, where the training is heavily influenced by Strasberg's approach, and the Soho based Giles Foreman Centre for Acting, which offers Strasberg based acting courses inspired by Reuven Adiv's work at the Drama Centre. Other Strasberg related courses are available at the Brian Timoney Actors' Studio, which offers intensive training courses in Central London and the Glasgow based UK Screen Acting Academy, which offers Strasberg inspired parttime acting classes at the University of Strathclyde. 
Even from this necessarily brief overview of UK based training opportunities, it is evident that Strasberg's work continues to prove attractive to a new generation of actors. Indeed, during the last few years the influence of Method based training in the UK has steadily grown and includes not just the work of Lee Strasberg, but also that of Sanford Meisner ${ }^{18}$ - who, alongside Strasberg, was one of the original members of New York's Group Theatre in the 1930s. What is it that accounts for this fairly recent surge in interest and the growing popularity of Method based training, both within subsidized $\mathrm{FE} / \mathrm{HE}$ actor training provision as well as privately funded schools?

Arguing that many of the most popular drama schools were established to serve a repertory theatre tradition that no longer exists, Sam Rumbelow asserts that Method based approaches allow for an expression of selfhood and personalization that is much more in tune with the diverse, multi-cultural environments from which many of today's acting students come. 'The world in which Stanislavski worked does not prevail in today's working environment'. ${ }^{19}$ As was indicated earlier, for Rumbelow, Lee Strasberg's Method - which he concedes has emerged from Stanislavski's System allows actors the opportunity to develop their craft via ' ...the primary flow of the self' (Ibid). Whereas in the past, British training technique focused on the need to train actors capable of transforming physically - in accordance with the demands of repertory programmes that were staged in large theatre spaces - more contemporary approaches have become increasingly sensitive to the changing context in which actors now work. During the last twenty-five years or so, the collapse of British Repertory theatre; the massive expansion of TV broadcasting - via cable, satellite and internet provision; the ever-increasing influence and aesthetics of so called 'Reality TV' and the cult of the celebrity; the increased levels of hybridity between different genres and traditions; as 
well as the influence of various socio-political changes that have taken place across British society more generally (increased social liberalism, a growth in immigration, changes in gender politics, and rising secularism, ) have brought about a shift in how we engage with and 'receive' different modes of performance - whether live or recorded - as well as the role and function of the 'performer'. Is the drama we are watching fictitious, real, verbatim, a documentary, a fantasy, live action, an animation, etc.? In such a landscape, the growth of acting methodologies that seek authenticity through an enhanced understanding of selfhood is perhaps hardly surprising.

Finally, and perhaps somewhat ironically, whist there may well be a great deal of truth in Rumbelow's contention that the world in which Stanislavski operated no longer prevails today, it remains compelling to discover that the guidance he offers actors prior to commencing work on a role seems every bit as important now as it ever was:

Every idea you have must be precisely substantiated and strictly determined. The questions - who, when, where, why, for what reason, how - which we asked so as to stir our imagination, helped us create a picture of our imaginary, illusory life with greater and greater definition...imagining "in general" without a well-defined, solidly based theme, is fruitless.' (Stanislavski 2008: 83)

\footnotetext{
${ }^{1}$ Stella Adler and Sanford Meisner were both members of the Group Theatre in New York, formed by Harold Clurman, Cheryl Crawford and Lee Strasberg in 1931. Uta Hagen was a celebrated actress and highly influential acting teacher, who based herself at the HB Studio in Greenwich Village, New York.

${ }^{2}$ From personal communication between Sam Rumbelow and the author $11^{\text {th }}$ August 2017

${ }^{3}$ Ibid

${ }^{4}$ In Strasberg at the Actors Studio: The Tape-Recorded Sessions compiled by Robert H. Hethmon (210: 91), Strasberg identifies just the first three areas of tension. However, in his book, $\underline{A}$ Dream of Passion 1988: 127-8, he references four areas of tension and even mentions a fifth - that of the
} 
lower and upper back area, which he suggests 'retain the impression of strong emotional experiences' (Strasberg 1988:129). In the Lee Strasberg Notes, however, edited by Lola Cohen (Cohen 2010: 9), Cohen identifies only the four included here.

${ }^{5}$ From personal communication between Sam Rumbelow and the author $11^{\text {th }}$ August 2017

${ }^{6}$ From personal communication with Peter MCAllister and the author $24^{\text {th }}$ July 2017

7 The work of Russian actor and director, Yevgeny Vakhtangov (1983-1922), was a significant influence on the development of Strasberg's methodology. A more detailed evaluation of the distinctions between Stanislavski and Vakhtangov is available in Hull, S Loraine (1985: 228-232)

${ }^{8}$ Excellent examples of this are articulated by David Krasner in his chapter entitled I HATE STRASBERG: Method Bashing in the Academy in Krasner, David (2000) Method Acting Reconsidered pp.28-34

${ }^{9}$ Uta Hagen, also a Method teacher, developed a series of 'object exercises' that have a similar aims to those of Strasberg. For these exercises, however, a much greater emphasis is placed on the importance of using real items of furniture etc. and, where necessary, of endowing such items with the particular values associated with the original items in the actor's life.

10 A more detailed reference to Freud's influence on Strasberg can be found in the companion article to this published in Stanislavski Studies Vol 4 Issue 1 pp.52-3

${ }^{11}$ From personal communication with Peter MCAllister and the author 24th July 2017

12 Ibid

${ }^{13}$ Stanislavski's discussion of the notion of public solitude can be found in Stanislavski, C $2008 \underline{\mathrm{An}}$ Actor's Work London: Routledge Chapter 5 -pp.86-118

${ }^{14}$ For further discussion of this aspect of Strasberg's work see Hull, Loraine S. 2012 [1985] Strasberg's Method - As Taught by Lorrie Hull USA: Hull-Smithers pp.131-147 and Hethmon, Robert H. Strasberg at the Actors Studio - Tape Recorded Sessions 2010 [1965] USA: TCG pp.102-104

15 See Strasberg's own A Dream of Passion (1988), Robert Hethmon's Strasberg at the Actors $\underline{\text { Studio }}$ (1965), Lola Cohen's The Lee Strasberg Notes (2010) and S Loraine Hull's Strasberg's Method (1985)

${ }^{16}$ For an excellent discussion of criticisms of this work see I HATE STRASBERG: Method Bashing in the Academy in Krasner, David (2000) Method Acting Reconsidered pp.28-34

17 For a fuller discussion of Strasberg's criticisms of the acting styles in English theatre see Hethmon Robert H (2010: 378-81)

18 For a discussion of Sanford Meisner's influence on British actor training see Shirley, D 'The Reality of Doing': Meisner Techniqe and British Actor Training in Theatre, Dance and Performance Training Vol.1 Issue 22010 pp.199-213 Routledge.

${ }^{19}$ From personal communication between Sam Rumbelow and the author $11^{\text {th }}$ August 2017

\section{Bibliography}

Cohen, Lola (ed.) The Lee Strasberg Notes. London: Routledge, 2010

Counsell, Colin. Signs of Performance - An Introduction to $20^{\text {th }}$ Century Theatre.

London: Routledge, 1996

Harrop, John. Acting. London: Routledge, 1992

Hethmon, Robert H (ed.) Strasberg at the Actors Studio - Tape Recorded Sessions

New York: Theatre Communications Group, 1965 
Hornby, Richard. The End of Acting - A Radical View. New York: Applause Books, 1992

Hull, S. Loraine Strasberg's Method - As Taught by Lorrie Hull USA: Hull-Smithers, 1985

Krasner, David (ed.) Method Acting Reconsidered. USA: Palgrave, 2000

Manderino, Ned All About Method Acting USA: Manderino Books, 1985

Moston, Doug 'Standards and Practices.' Chapter 8 in Krasner, David (ed.)

Method Acting Reconsidered. USA: Palgrave, 2000

Shirley, D His Dream of Passion: Reflections on the Work of Lee Strasberg and his Influence on British Actor Training Stnislavski Studies 4, no.1 (2016): 47-62 Routledge

Stanislavski, K An Actor's Work - Translated by Benedetti, J London: Routledge, 2008

Strasberg, Lee. A Dream of Passion: The Development of the Method. New York: Plume Books 1988

Whyman, Rose The Stanislavsky System of Acting CUP, 2008 